\title{
Review \\ The Present and Future Role of Microfluidics for Protein and Peptide-Based Therapeutics and Diagnostics
}

\author{
Edward Weaver ${ }^{1}$, Shahid Uddin ${ }^{2}\left(\mathbb{D}\right.$, David K. Cole ${ }^{2}\left(\mathbb{D}\right.$, Andrew Hooker ${ }^{2}$ and Dimitrios A. Lamprou ${ }^{1, *(\mathbb{C}}$ \\ 1 School of Pharmacy, Queen's University Belfast, 97 Lisburn Road, Belfast BT9 7BL, UK; eweaver01@qub.ac.uk \\ 2 Immunocore Ltd., 92 Park Drive, Milton Park, Abingdon OX14 4RY, UK; \\ shahid.uddin@immunocore.com (S.U.); David.Cole@immunocore.com (D.K.C.); \\ Andy.Hooker@immunocore.com (A.H.) \\ * Correspondence: d.lamprou@qub.ac.uk; Tel.: +44-(0)-28-9097-2617
}

check for updates

Citation: Weaver, E.; Uddin, S.; Cole, D.K.; Hooker, A.; Lamprou, D.A. The Present and Future Role of Microfluidics for Protein and Peptide-Based Therapeutics and Diagnostics. Appl. Sci. 2021, 11, 4109. https://doi.org/10.3390/app11094109

Academic Editor: Carla Sardo

Received: 8 April 2021

Accepted: 28 April 2021

Published: 30 April 2021

Publisher's Note: MDPI stays neutral with regard to jurisdictional claims in published maps and institutional affiliations.

Copyright: (c) 2021 by the authors. Licensee MDPI, Basel, Switzerland. This article is an open access article distributed under the terms and conditions of the Creative Commons Attribution (CC BY) license (https:/ / creativecommons.org/licenses/by/ $4.0 /)$.

\begin{abstract}
The implementation of peptide-based molecules within the medical field has vast potential, owing to their unique nature and predictable physicochemical profiles. However, peptide therapeutic usage is hindered by delivery-related challenges, meaning that their formulations must be altered to overcome these limitations. This process could be propelled by applying microfluidics (MFs) due to its highly controllable and adaptable attributes; however, therapeutic research within this field is extremely limited. Peptides possess multifunctional roles within therapeutic formulations, ranging from enhancing target specificity to acting as the active component of the medicine. Diagnostically, MFs are well explored in the field of peptides, as MFs provide an unsullied platform to provide fast yet accurate examinations. The capacity to add attributes, such as integrated sensors and microwells, to the MF chip, only enhances the attractiveness of MFs as a diagnostic platform. The structural individuality of peptides makes them prime candidates for diagnostic purposes, for example, antigen detection and isolation. Therefore, this review provides a useful insight into the current applications of MFs for peptide-based therapy and diagnostics and highlights potential gaps in the field that are yet to be explored or optimized.
\end{abstract}

Keywords: microfluidics; peptides; proteins; amino acid-based biologics; theranostics; formulation; nanomedicine

\section{Introduction}

Peptide-based molecules fall into two distinct classes. The first class consist of peptides, which are short chains of amino acids (AAs), generally considered to be 2-50 AAs in length [1-3], that depending on their chemical composition, can perform a wide variety of functions, both for diagnostic and therapeutic purposes. With 22 well-known proteinogenic AAs [4] and many more nonproteinogenic AAs, the variability of peptide composition is extremely vast. Proteinogenic AAs are essential for normal human function, regulating metabolism, growth and repair, among other processes [5]; however, they can also be exploited for their medicinal qualities. Over 7000 naturally occurring peptides have been identified in nature [6], with much more able to be synthesized artificially, providing a huge library of molecules with potentially life-sustaining effects. Common peptide-based medicines, such as adalimumab (TNF inhibitor) and insulin, are used daily by millions of people for an extensive range of conditions, namely Crohn's disease, diabetes mellitus, and rheumatoid arthritis, among others. The second class of peptide-based molecules consists of proteins, generally $>50$ AAs and can have complex secondary structures. This class includes enzymes and antibodies.

Peptide therapeutics are some of the most valuable medicines available [6]; however, their formulations are far from optimized. All peptide medicines must be delivered parenterally [7], often intravenously, due to the degradative process that occurs upon oral administration, which, despite being less convenient for the patient, still allows the delivery 
of life-saving medicines. Peptide drugs frequently possess high selectivity and potency while sustaining an agreeable safety profile, for example, novel antimicrobial peptides $[8,9]$ and chemotherapeutic agents [10]. Their chemical nature often makes their metabolism predictable [11], which is very useful for administration, distribution, metabolism, and excretion (ADME) calculations; however, frequently, the unmodified peptide will have a very unfavorable ADME profile. For this reason, administrative formulation methods like nanoencapsulation, pegylation and peptide-implant reservoirs must be exploited to allow optimized delivery of the peptides.

Due to the unique nature of proteins, their diagnostic attributes are also prevalent in many areas of healthcare, including imaging agents for pregnancy tests. Target specificity is one of the major attributes that peptide-based molecules possess, as their individual AA composition extends peptides to be prime candidates for diagnostic techniques, such as antibody isolation, radiotherapeutic imaging and enzyme detection [12]. Peptidebased molecules are already established for diagnostic purposes; however, due to recent nanotechnological advances, a new generation of peptide-based diagnostics could be on the horizon.

Peptides have a broad scope of utility, owing to their unique and adaptable pharmacokinetic (PK) and pharmacodynamic (PD) properties, making them ideal candidates for theranostic applications. Depending upon the chemical composition of a peptide chain, attributes, such as amphiphilicity or a high volume of distribution (Vd), may be demonstrated [13]. Knowledge of PK and PD allows analysis of a molecule's potential toxicological profile. Peptide-based products on the market, such as insulin glargine and denosumab, are tested rigorously to establish in-depth safety profiles to prevent harm upon use. Depending upon the peptide's formulation, e.g., nanoencapsulation or pegylation, the toxicology profiles will vary. For example, toxicology profiles relating to nano-encapsulated peptides are speculated to possess lower toxicity than the unmodified peptide [14], while pegylated molecules are compared to their un-pegylated counterparts are more toxicologically similar [15]. Self-assembled peptide nano-therapies offer a versatile system design and high levels of efficacy while maintaining a high safety profile, which is an ideal combination for patient care. Outside the area of MFs, peptides have been successfully employed in a theranostic capacity [16]. However, as is the main difficulty with peptide manipulation, reliable and efficacious formulation into a functioning theranostic medium is far from being optimized.

Peptide functionality can be altered to be idiosyncratic depending on their composition. To name a few leading uses, summarized in Figure 1, they can be used for theranostic purposes to:

- Assist in delivering an active pharmaceutical ingredient (API), both as carrier material and as a functionalized epitope, to provide region-specific delivery [17].

- Act as the API within a formulation;

- Provide unique binding regions to assist with the isolation of specific receptors [18];

- Enhance the quality of diagnostic imaging techniques [19].

This review will discuss in-depth how MFs can be utilized as an accomplished synthetic process to produce peptides or formulate them into medicine while also highlighting its capacity to provide a contemporary theranostic function. 


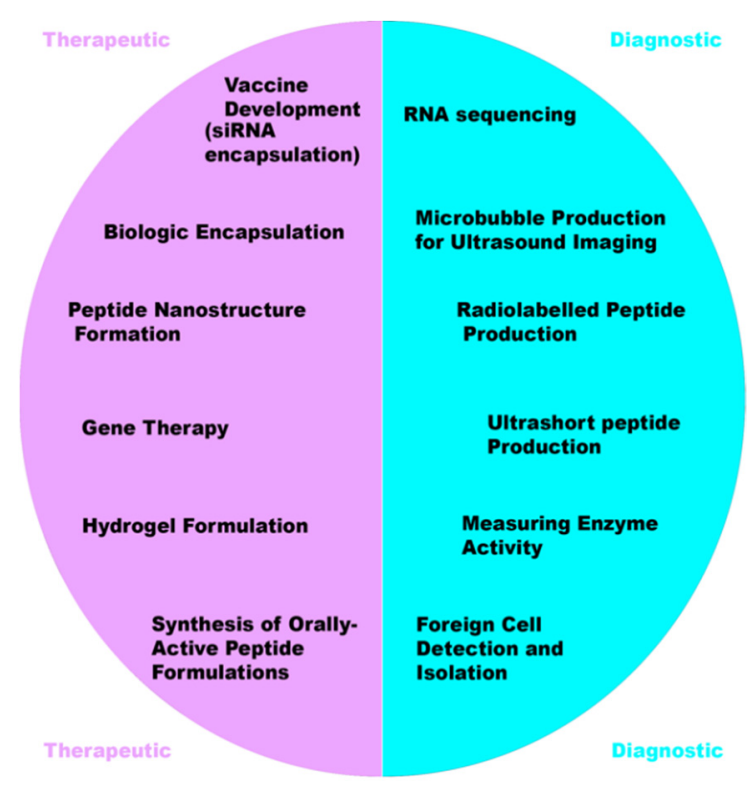

Figure 1. Summary of therapeutic and diagnostic applications for MFs discussed in this review.

\section{Microfluidics}

Microfluidics (MFs) has been used for decades, with many of its advancements coming in the late 1980s [20]. It was not until 2005 that MFs was recognized as an innovative realtime diagnostic platform that could be exploited for many functions [21]. The process of MFs allows precise control over the combination of fluids within a microliter-sized environment. The system's capacity to evolve to specific needs by adjusting component parameters is one of the most sought-after features of this system. Parameters, including total flow rate (TFR), flow rate ratio (FRR), and chip design, to name a few, are factors that can be adjusted to alter the outcome of the process. A breakdown of common attributes present in MFs is shown in Figure 2.

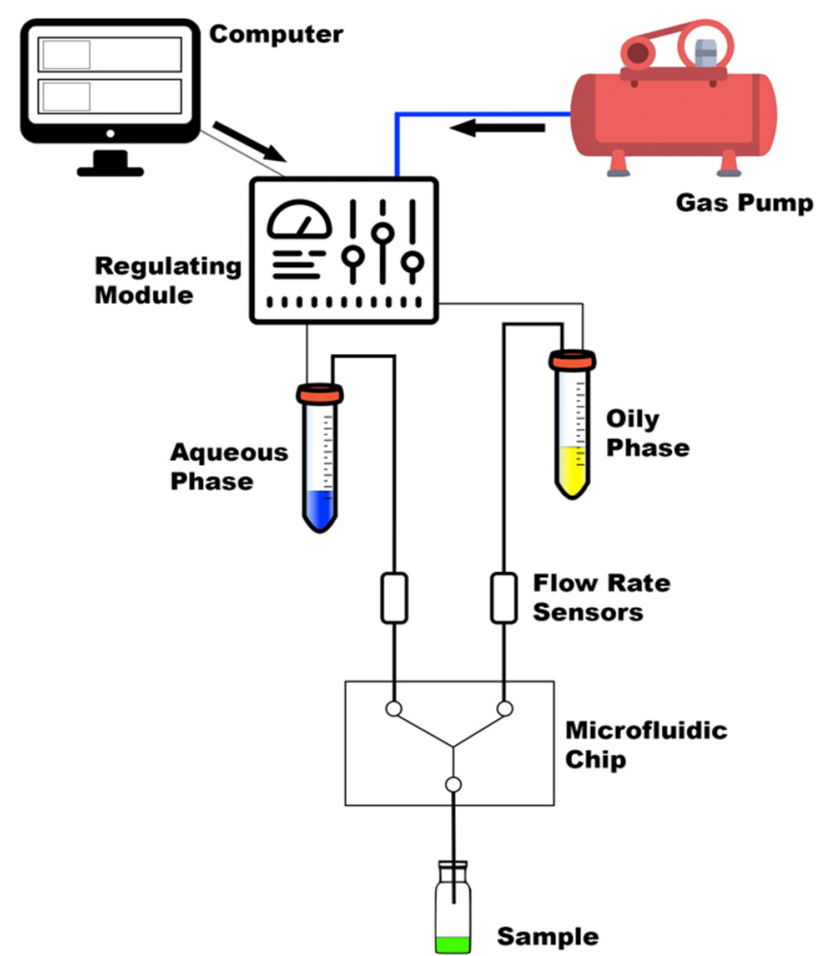

Figure 2. Summary of the different components in a basic MF system. 
Since its discovery, MFs have been used for various applications, even applications outside of medicine, for example, improving industrial extraction methods of crude oil [22] or the fabrication of complex electrical components [23]. However, its primary use is within medical, biomedical and genetic fields, as its adaptiveness lends itself to generating highquality results over a broad spectrum of operations. As mentioned, the analysis of peptides within the MFs field is limited, especially therapeutically, although it has well-established usage for non-peptide processes, for example, investigating bacterial micropropulsion mechanisms [24] or acting as an "organ-on-a-chip" [25]. The latter use mentioned here allows accurate in vitro measurements, owing to the capacity of MFs to design the chip to be uniquely imitative of specific environmental conditions.

The choice of material for fabricating the MF chip is an important factor to consider, as individual materials are incompatible with processes as detailed in Table 1. Most modern peptide research uses chips fabricated from the elastomer polydimethylsiloxane (PDMS), a highly modifiable material used in conjunction with 3D printing. Depending upon the role of the MF system in the assay, the right material must be chosen.

Table 1. Summary of associated properties for various materials used as microfluidic chips [26-29].

\begin{tabular}{|c|c|c|c|}
\hline Glass/Silicon & PDMS & Hydrogels & Paper \\
\hline \multicolumn{4}{|c|}{ Advantages } \\
\hline $\begin{array}{c}<100 \mathrm{~nm} \text { channel dimensions } \\
\text { possible [26] }\end{array}$ & Easy and cheap to synthesize & $\begin{array}{c}\text { Can mimic extracellular } \\
\text { environment }\end{array}$ & $\begin{array}{l}\text { Regions can be modified to } \\
\text { be hydrophobic }\end{array}$ \\
\hline $\begin{array}{c}\text { Reduces cost of processes, } \\
\text { such as capillary } \\
\text { electrophoresis [26] }\end{array}$ & High level of adaptability & $\begin{array}{l}\text { Useful for cell encapsulation } \\
\text { for 3D cultures [27] }\end{array}$ & $\begin{array}{l}\text { Useful for controlling } \\
\text { liquid absorption }\end{array}$ \\
\hline Low permeability to oxygen & $\begin{array}{l}\text { Oxygen permeability allows } \\
\text { for cell culture assays [27] }\end{array}$ & & Low cost [28] \\
\hline Resistant to organic solvents & $\begin{array}{c}\text { Allows nanometer-resolution } \\
\text { from 3D printing } \\
\text { High elasticity }\end{array}$ & & $\begin{array}{l}\text { External pump, e.g., gas not } \\
\text { necessarily required [28] }\end{array}$ \\
\hline \multicolumn{4}{|c|}{ Disadvantages } \\
\hline $\begin{array}{l}\text { High-cost of initial } \\
\text { microfabrication }\end{array}$ & $\begin{array}{l}\text { Low compatibility with } \\
\text { organic solvents }\end{array}$ & Low-level resolution [29] & $\begin{array}{c}\text { Low scope of detection } \\
\text { Properties }\end{array}$ \\
\hline Valve fabrication is difficult & $\begin{array}{c}\text { Absorbent for small } \\
\text { hydrophobic molecules }\end{array}$ & $\begin{array}{l}\text { Poor for } \\
\text { microfabrication methods }\end{array}$ & $\begin{array}{l}\text { Unsuitable for liquids with } \\
\text { low surface tension }\end{array}$ \\
\hline $\begin{array}{l}\text { Cannot be used for } \\
\text { cell cultures }\end{array}$ & & & Limited applications for MFs \\
\hline
\end{tabular}

\section{Therapeutic Applications of Peptides}

The application of peptides for medicinal use has exploded in recent years owing to their immense potential for therapeutic effect. Such applications include monoclonal antibodies (MABs) for cancer therapy and infectious disease prevention [30], vaccine synthesis using RNA (including the COVID-19 vaccine) [31,32] and newer uses for regenerative medicines [33], to name a few.

A common method to circumvent peptide-based formulation issues is by formulating the peptides within a nanocarrier vessel, for instance, a nanoparticle (NP). Different NPs have been synthesized in an attempt to effectively manipulate peptide APIs, such as hybridmagnetic NPs [34], nanoemulsions, liposomes, solid lipid nanoparticles (SLNs) [35] and polymer NPs (e.g., chitosan) [36]. All forms of NP have their own merits and drawbacks, and the method of synthesis can have a large impact on particle characteristics, irrespective of the type of NP being produced. The NP allows a certain level of customization to the medicine, offering the opportunity to provide target-specific delivery via either the NP's shell material properties, or by the modification of the shell with specific chemical groups to increase target receptor affinity. The NP also provides protection for the peptide against 
the broad-spectrum of peptidases present within the human body by providing a physical barrier to the degradative enzymes [37].

Formulation of peptides into NPs has been achieved in various ways. However, the processes are far from being optimized and often fall short compared to the standards of industrial medicine synthesis that are implemented for other medicines. Methods, such as unilamellar fusion and thin-film hydration, have been proven to encapsulate peptides [38], but the methods have not yet rectified issues surrounding effective control of particle size and polydispersity index (PDI), as well as possessing unfavorable encapsulation efficiencies [39]. Thus, it has been theorized that a highly controllable system like MFs could be the solution to providing a high standard of encapsulation of peptide molecules within various NPs. A brief summary of method attributes is shown in Table 2.

Table 2. Advantages and disadvantages of three methods used for peptide nanomedicine synthesis.

\begin{tabular}{ccc}
\hline Microfluidics & Unilamellar Vesicle Fusion & Thin-Film Hydration \\
\hline $\begin{array}{c}\text { Allows synthesis at room temperature } \\
\text { Good control over PDI and particle size } \\
\begin{array}{c}\text { Easy method to scale-up } \\
\text { High encapsulation efficiencies [41] } \\
\text { Continuous process }\end{array}\end{array}$ & $\begin{array}{c}\text { Advantages } \\
\text { Process can be controlled via electrostatic } \\
\text { manipulation [40] }\end{array}$ & $\begin{array}{c}\text { Simple method } \\
\text { Acceptable encapsulation efficiencies for } \\
\text { smaller peptides }\end{array}$ \\
\hline $\begin{array}{c}\text { Material interactions with MF chip } \\
\text { Requires initial high-cost system }\end{array}$ & Less control over PDI and particle size \\
& Affected greatly by temperature & $\begin{array}{c}\text { Less control over PDI and particle size } \\
\text { Produces heterogeneous particle } \\
\text { population that requires } \\
\text { extrusion/sonication [42] }\end{array}$ \\
\hline
\end{tabular}

The introduction of peptides into the MF system to fabricate nanomedicines (NMs) is a novel approach, which is already showing huge potential within the nano-formulation field. In 2020, the COVID-19 virus expedited research into RNA-based vaccines as many companies, including BioNTech/Pfizer and Moderna, relied on the genetically sequenced peptides for the efficacy of their vaccines [43]. The utilization of MFs to synthesize RNAbased vaccines has been shown to be an effective means of RNA encapsulation, achieving favorable synthetic attributes, in particular encapsulation efficiencies of $>99 \%$ [44].

This area of research represents a huge opportunity for advancing vaccine technology, as MFs can be adapted to allow NP modification, which in turn increases target specificity. Most research performed revolving around RNA manipulation within the MF system is based upon RNA sequencing, which is an extremely effective tool [45,46]. Discovering the heterogeneity of cellular information is essential to many biomedical applications, for instance, vaccine development, suggesting that MFs could provide a "door-to-door" approach for vaccine production, as MFs can provide both the target identification platform via sequence isolation, as well as a synthesis system to formulate the final vaccine. The system's high throughput capacity allows multiple tests to be conducted within a limited timeframe, which would have been perfect in response to developing a COVID-19 vaccine.

One of the key elements inhibiting using peptides as nanocarriers is the lack of reliable formulation reproducibility and general disadvantageous nanocarrier properties, such as large sizes and high PDI values. By utilizing the controlled, small volume environment provided by the MF platform, researchers have begun to observe a change in this trend. The self-assembly of peptide chains from amino acids highlighted by Chan et al. and proven by $\mathrm{Ni}$ et al. indicate a huge potential for implementing peptides into the nanocarrier field. Frequently, the function of peptides for nanoformulations is to act as membrane epitopes attached to a functional polymer, such as chitosan or polylactic co-glycolic acid (PLGA) $[47,48]$. However, due to the emergence of MFs, it is starting to become feasible 
to produce NP membranes consisting fully of peptides. These peptide nanocarriers can possess desirable properties, including increased cell permeation [49], region-specific delivery [50] and a high degree of potential for modification based upon their unique chemical makeup. As a result, of the controlled synthesis, using extrusion and sonication is rarely needed for formulations produced by MFs, which ensures that the time taken for production is minimal.

\subsection{Peptide Encapsulation}

Formulation of peptides within liposomes is possible using MFs due to the ability of certain lipids, e.g., 1,2-dimyristoyl-sn-glycero-3-phosphocholine (DMPC), to self-assemble into lipid nanostructures upon contact with aqueous media. Due to the amphiphilic nature of phospholipids, when in the presence of an aqueous medium, self-assembly occurs caused by noncovalent interactions forcing lipophilic areas of the molecules to a geometric state of low entropy [51], as seen in Figure 3. This principle has been harnessed during a novel attempt to encapsulate large biologic drugs, for example, ovalbumin and bovine serum albumin (BSA) [41]. The encapsulation of biologic drugs performed in this study produced liposomes of drastically smaller sizes and PDIs than obtained via previous methods, for instance, sonication or extrusion [41], as well as importantly increasing encapsulation efficacy.

Increasing the encapsulation efficiency is crucial for biologic molecules due to their cost as even commonly used biologics, such as insulin, can cost over GBP 200 for $50 \mathrm{mg}$, which has been a limiting factor for scaling up production of previous methods to industrial levels. With further research encapsulating other biologics, it is possible that a financially viable method could be devised to produce these biologic formulations, which could even lead to groundbreaking medicines, including orally active insulin preparations. Evidently, as research in this area is limited, it still requires much work to determine the exact MF parameters that will be optimal for biologic encapsulation, or even that biologics are susceptible to encapsulation via an MF route. However, the evidence suggests so far that MFs offer a very promising synthetic method to produce such formulations.

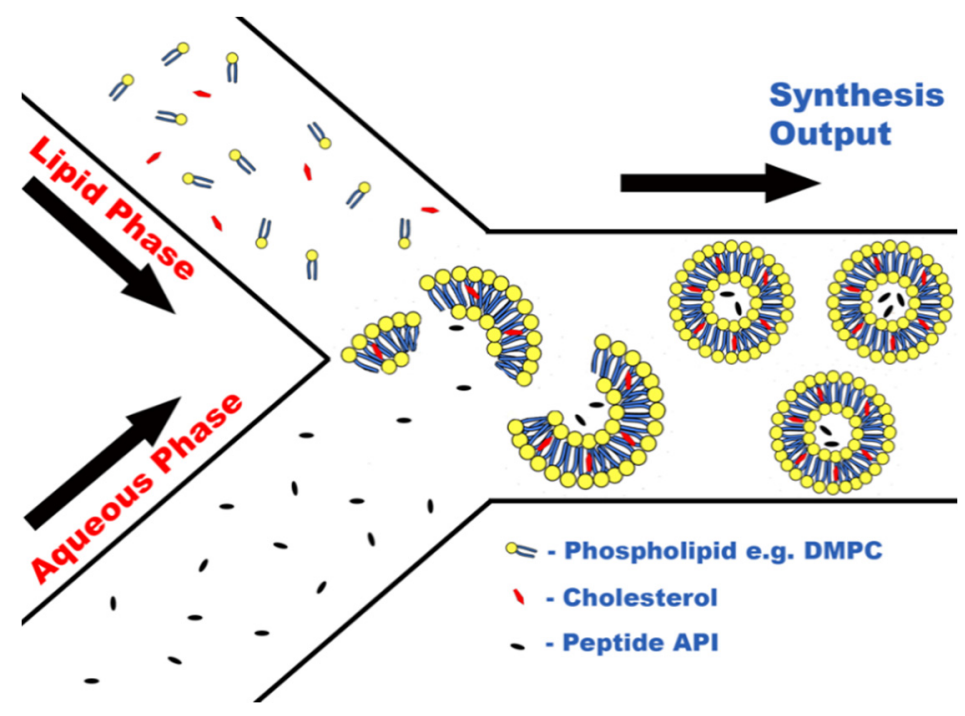

Figure 3. Concept of peptide encapsulation within liposomes via liposome self-assembly.

\subsection{Hydrogels and Peptide Antibiotics}

The production of peptide-based biomaterials via MFs is attractive as they possess a low level of immunogenicity, and prolonged-release formulations, such as biologic hydrogels, will degrade slowly over time, via natural processes, into non-toxic materials [52,53]. Recent work performed utilizing the prolonged curative properties of peptide hydrogels allowed a double-pronged approach to wound healing via an MF-assisted process [54]. 
Peptide hydrogels possess a structure similar to the extracellular matrix, making them an ideal biocompatible medium for the controlled release of APIs. MFs were employed to synthesize a compact fibrous network of alginate to provide an optimal setting for the self-assembly of peptides onto the structure. The use of peptides on the structure also allowed the addition of a secondary API, the antibiotic lincomycin, within the hydrogel; hence providing two APIs to provide a therapeutic effect. The novel approach of using peptides within the structure ensured that the wound healing process could be optimized by providing both the anti-inflammatory benefits of prolonged-release peptide therapy, as well as introducing antibiotic activity.

It is possible that the process designed by Jain et al. [55] would be adaptable to a microfluidic approach, which exploited ultrashort peptides (USPs) to control gold NP synthesis within a complex hydrogel structure. USPs are short chains of amino acids (approximately 3-7 amino acids) that can be used to provide unique interactions with external environments. Owing to the predictable chemical behavior of peptides, they have been shown to be exploited to assist with NP shape control. NP shape is an important factor to consider as it affects overall PDI values, and it can also affect the thermal stability of a formulation or encapsulation efficacy. For example, nickel-based NPs in a spherical shape have better heat-transference properties than a disc shape [56].

Owing to increased pathogen drug resistance, the production of novel antimicrobials is limited, which is why a new area of antimicrobials in the form of peptide therapeutics should be explored. Despite the categorization of over 3000 AMPs, currently, only 7 antimicrobial peptides (AMPs) are approved for clinical use by the FDA [57], owing mainly to a lack of clinical efficacy. Bioassays performed using an MF design allow detecting antimicrobial activity. However, when compared to the traditional format of measuring via 96-well plate analysis, the results obtained were dissimilar, owing to differing oxygenation levels during incubation subjected to each system. The 96-well plate was exposed to a greater level of oxygen than the MFs assays, causing incomparability of the systems and hence the results of this study were inconclusive [57]. However, there is strong potential for future research in this area to explore different approaches for obtaining AMP activity using MFs. Conceptually, it is clear that MFs can be employed for this purpose, and there is an acute need for a new bioassay method, so this is an area that should be developed further.

\subsection{Gene Therapy}

Gene therapy is an area of medicine that could potentially have a massive impact on our perceived view of gold-standard healthcare. However, it is constantly shrouded by controversy and negative implications, as well as proving to be a difficult procedure to perfect. The advancement of MF designs could impact this area as current investigations into the MF synthesis of double-stranded DNA (dsDNA) carriers are at the forefront of enhancing gene delivery to specific targets [58]. Carrier materials like graphene oxide (GO) are versatile materials that, when unmodified, possess the ability to integrate single-stranded DNA or RNA onto their structure via distributed $\pi-\pi$ interactions. Modification via MFs is required to alter the charge of the GO structure to allow dsDNA bonding, as seen in Figure 2. Coating of the GO with a cationic lipid, such as 1,2-dioleoyl-3trimethylammonium-propane (DOTAP), via MFs, increases the overall surface electrostatic charge, complementary to that of dsDNA. This lipid coating increased cellular uptake of DNA from $48.8 \% \pm 6$ using unmodified GO to an improved $93.9 \% \pm 0.2$. As one of the main inhibitors of gene therapy is achieving suitable gene concentrations for therapeutic effect, this progress is revolutionary. The carrier is required to prevent the susceptible DNA from degradation upon administration, as well as increasing gene transfection [59].

\subsection{Oral Administration of Peptide-Based Medicines}

Finally, for peptide therapeutics, a zealous approach to the synthesis of orally administered peptide medicines was performed using a multilamellar delivery system for the co-administration of an anti-diabetic peptide, glucagon-like peptide-1 (GLP-1), along- 
side another molecule, dipeptidyl peptidase 4 inhibitors (DPP4i) [60]. Currently, the only administration route for GLP-1 is parenteral, which leads to lower patient medicine adherence [61]. The natural degradation time for GLP-1 post-administration is approximately 2 min [62] due to rapid degradation by the enzyme dipeptidyl peptidase 4 . Upon formulation into the dual-action functionalized NPs, hypoglycemic effects of the GLP-1 could still be observed $6 \mathrm{~h}$ after administration.

The synthesis of this formulation is complex, requiring multiple stages and multiple vessel materials: An initial NP was fabricated from PLGA and mesoporous silicon (PSi). This NP had additional surface functional groups of chitosan (CS) (to aid mucoadhesion) and cell-penetrating peptides (CPP), which assist the delivery of NP contents through the lipid bilayer of a cell. This NP contained the API GLP-1 and can be seen in Figure 4. MFs were then employed to further encapsulate this NP within an enteric coating material, hydroxypropylmethylcellulose acetyl succinate (HPMC-AS). The DPPi4 was only added upon final encapsulation alongside the HPMC-AS, which protected the two APIs against the inhospitable conditions exhibited upon oral administration. As research into orally administered peptide-based medicines is developed, a wide range of new patient-friendly, peptide-based medicines could begin to emerge. According to a 2019 study, parenterally administered medicines consistently had greater non-adherence rates than oral formulations [61], potentially leading to a lower quality of life.

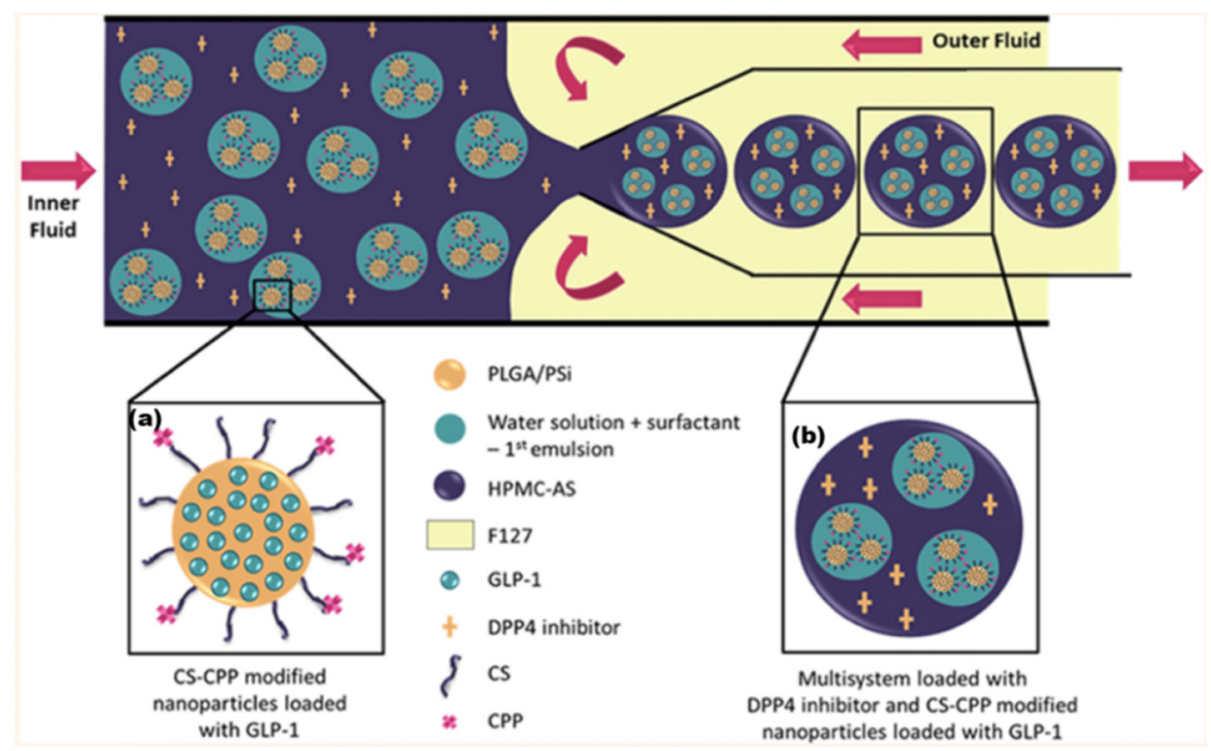

Figure 4. (a) Initial NP produced via the double emulsion method. (b) Final multilayered formulation produced by mixing emulsified particle (a) with HPMC-AS/DPP4i solution. Adapted with permission from Araújo et al. [60] Copyright 2015 American Chemical Society.

\section{Microfluidics as a Diagnostic Platform}

Theranostics is an established technique that couples the process of diagnosis and therapy. Although there is already a large amount of evidence pointing towards the efficacy of these techniques, there are still areas to be explored or optimized. MFs have only recently been used as a means to provide such treatment, and a few potent applications for the system catered to theranostics are listed below, showing how broad the scope of MFs can be for this medium.

Despite the promise that peptide-based molecules offer, it is important to consider their limitations within the platform too. Properties of peptides, including high susceptibility to temperature and high production costs (to obtain high molecule specificity), can restrict their feasible medical use [3]. MFs can decrease this impact for diagnostic applications by providing individual small-volume environments, which require minimal materials for processing. 


\subsection{Microfluidics for Peptide Imaging}

The formation of microbubbles to assist ultrasound imaging has traditionally been performed via various methods, including membrane emulsification, mechanical agitation or laser cavitation [63]. However, MFs have been found to produce microbubbles of a higher quality than the aforementioned techniques. Bubbles with consistent sizes (approximately $10 \mu \mathrm{m}$ diameter) can be produced by combining a continuous aqueous phase with a gas phase (e.g., perfluorobutane $\left.\left(\mathrm{C}_{4} \mathrm{~F}_{10}\right)\right)$ within the micron-sized channels of the MF chip [64] Depending upon the chip's design, two major methods for microbubble synthesis can be performed using MFs. First, a standard T-junction method can be used, which combines two separate phase streams within the chip at a "chaos point". The microbubbles produced via this method appeared to be less consistently sized than using the second method; flow focusing. Flow focusing exploits the geometric properties of the chip to produce uniform and smaller microbubbles from a pre-mixed stream of phases. A diagrammatic representation of these processes can be seen in Figure 5.

The microbubbles are used to create contrasting areas of imaging within the body to optimize the functionality of ultrasound scanning. It is also possible to modify the process by simple modification of the chip design to incorporate multiple inlets, affecting the final properties of the bubble, such as attaching additional imaging modalities to the microbubbles or encapsulating APIs within the structure. Microbubbles have been functionalized with fluorescent and magnetic resonance to ameliorate the imaging capacity of the formulation, as well as allowing the addition of peptide moieties onto the shell structure to increase the target specificity of the imaging medium [65]. It was concluded that varying the capillary size within the microfluidic chip had a dramatic effect upon the final size of the microbubble produced. As this area of research expands alongside the general use of peptide formulations within the system, future microbubble formulations will gain exponential levels of adaptability to help achieve their optimized imaging potential.

(a)

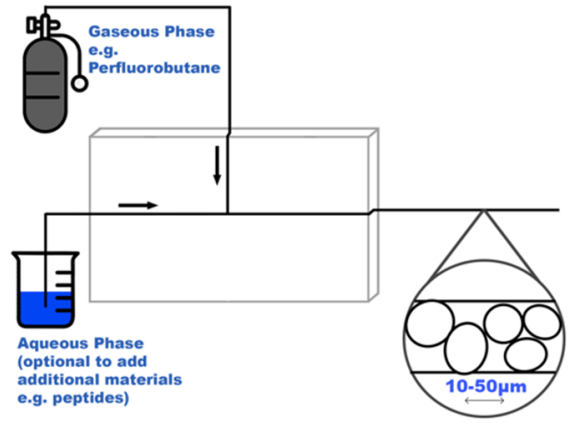

(b)

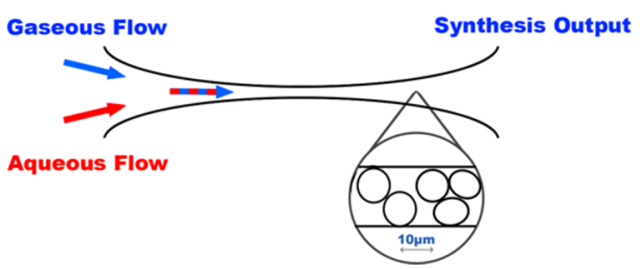

(c)

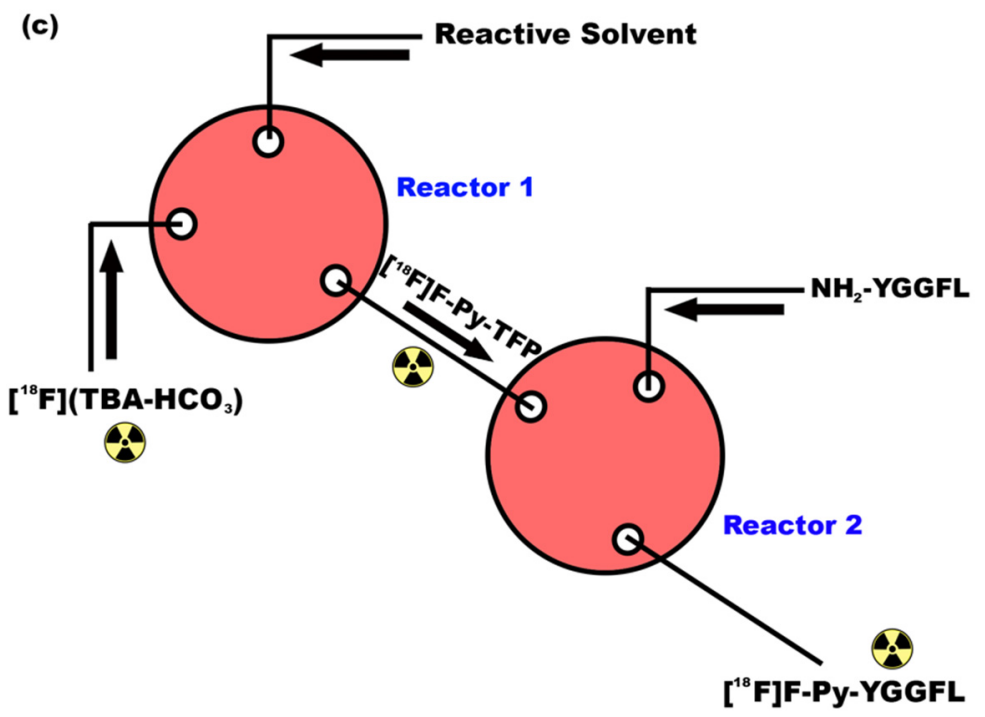

Figure 5. Microbubble formulation methods using MFs, as suggested by Pulsipher et al. using (a) t-junction incorporation and (b) flow focusing; (c) radiolabelled peptide production, adapted from Cumming et al. [66].

When processes are time-dependent, for example, the synthesis of radiolabelled atoms, MFs offer an extremely effective route to establish quick synthesis whilst maintaining product quality. Prior to MFs implementation, synthesis of the peptide radiotracer $\left[{ }^{18} \mathrm{~F}\right]$ F-Py-YGGFL from anhydrous ${ }^{18} \mathrm{~F}$, a two-step reaction, required a process that took over an hour, which led to decreased yields as the half-life of ${ }^{18} \mathrm{~F}$ is only $110 \mathrm{~min}$ [67]. Using an automated MF system, which employs two separate microfluidic reactor environments in series, within the same system, it is possible to reduce this time to just $8 \mathrm{~min}$, as shown in 
Figure 5 [66]. As the system operated in two separate reactors, it is possible to isolate the environmental conditions from each reactor in case different temperatures are optimal for individual steps. The MF process ensured minimal time-based degradation, which meant that yields for the process were higher $(28 \%)$ compared to traditional methods.

The applications of radiolabelled peptides exist in the field of oncology in vivo imaging (e.g., PET scans), as they are non-toxic, effectively renally excreted due to their small size and possess low levels of immunogenicity. The premise of using multiple MF chips/reactors in series is an effective way that the system design can be manipulated to perform complex tasks, including synthesizing peptide conjugates, as seen above. There are also other radiolabelled atoms, ${ }^{64} \mathrm{Cu}$ and ${ }^{68} \mathrm{Ga}$, that have been conjugated with peptides via MFs [68], which both show a superior synthesis method compared to conventional means, allowing an increase of yield from $2-4 \%$ to approximately $26 \%$, as well as a $200-2000$-fold decrease in precursor materials required. Peptide conjugates are a common form of peptide modification as it provides the peptide with additional capacities, whether that be half-life extension or receptor-binding manipulation.

\subsection{USP Diagnostics}

USPs, Figure 6, have been observed to self-assemble into nanofibers upon forceful contact with aqueous media [69]. Ni et al. employed this factor within a microfluidic network to manufacture a peptide-based nanomedicine, possessing both a diagnostic attribute in the form of an imaging tool, as well as allowing target-specific delivery of APIs. The presence of USP nanofibers can be detected using optical imaging probes alongside second-harmonic microscopy [69]. The benefit of using USPs in this process is that the chemical makeup of the nanofibers can be tailored to selectively target specific cells with known antigens, such as rapidly proliferating cancerous cells. Research in this area so far is limited to using curcumin as the API. However, it acts as a solid pharmaceutical marker in terms of the potential of this formulation.

In vitro tests determined that the USP nanofibers acted as a prolonged-release formulation but noted that peptide degradation due to naturally occurring proteases in vivo might affect these results. It is possible to minimize this degradative effect by using unnatural D-amino acid-based peptides [53], which possess near-identical physicochemical properties but are resistant to protease-mediated hydrolysis in vivo [70]. This technology, if developed, could allow real-time monitoring of the therapeutic effect provided by a medicine. USPs come at a relatively low cost due to their size, which adds to the attractiveness of the process. Their use as a nanocarrier has been displayed to act as a controlled release formulation, allowing the delivery of curcumin to exceed 6 days, compared to the usual blood half-life of 5-10 $\mathrm{min}$ [69].

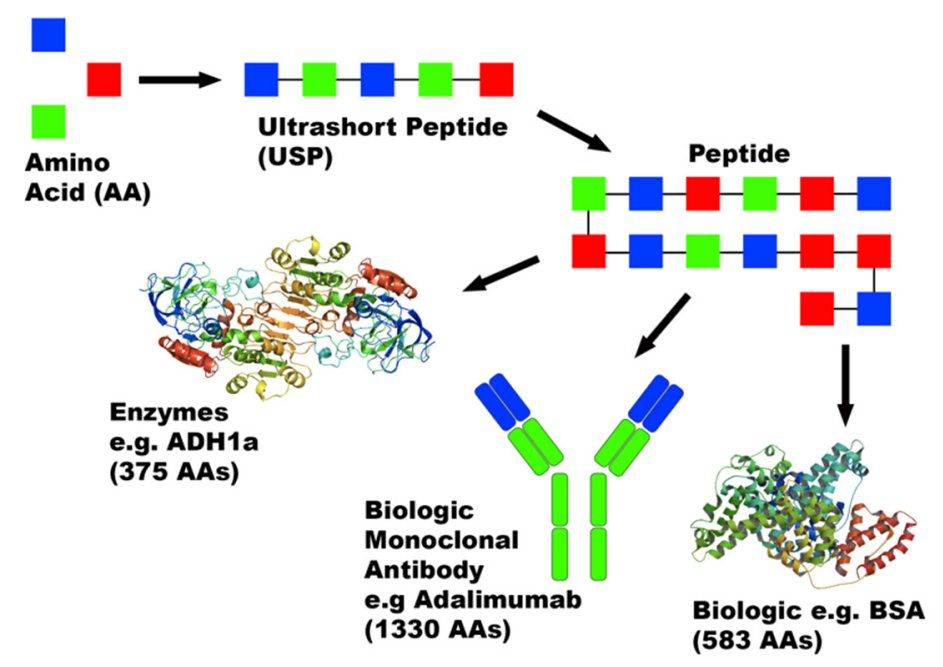

Figure 6. Capacity of peptides to form molecules for multifunctional applications. 


\subsection{Enzyme Activity and Biomarker Detection}

Measuring enzyme activity using an MF platform is not necessarily a contemporary idea, as many MF designs are centered around this [71,72]. However, due to recent advances in neighboring fields, namely additive manufacturing (AM) and nano-detection, the capacity for MFs to act as an area-leading platform has been propelled. Complex MF structures can be printed with high resolution to allow for precise control and monitoring of the environment within the MF chip. Recent enzyme studies using MFs [73] incorporate hydrodynamic traps within the MF chip to monitor an enzyme's activity, like Granzyme B, to determine an individual's response to therapeutic treatment and improve prognosis [74]. This type of assessment offers a high standard for determining clinical response as it focuses on single-cell activity, using a life (rather than fixed) cell [73]. By exploiting this fact, it is possible to measure a cell's response over a prolonged duration of time, giving a clearer image of a patient's response to therapy. If this technique were scaled up to other monitoring practices, personalized medicine optimization would be a far more achievable goal than currently possible, which could help relieve the economic burden on healthcare systems.

In a similar principle to the hydrodynamic traps used by Briones et al., peptide antibodies within micro-wells or via specialized surfaces on the MF chip can be used to isolate specific cells during identification assays $[75,76]$. Complementary antibodies to target receptors are immobilized onto the surfaces of the chip. Then blood samples are passed through the chip to perform the evaluation. This process is an effective tool used to act as an early detection test for diseases. In the case of studies performed by Varillas et al., circulating tumor cells (CTCs), which are the root cause of metastatic cancer, and cancer stem-like cells (CSCs) were targeted within the system. Owing to the adaptability of the chip, multiple antibodies were present within the chip, allowing detection of multiple different CTC biomarkers, for example, epithelial cell adhesion molecule (EpCAM) and a CSC biomarker, CD133. Current testing methods, such as EpCAM-based isolation, are used as a standard test for these molecules. However, false-negative results are observed occasionally with this method. The microfluidic isolation method appeared to give a higher level of accuracy than its testing counterparts, although more research must be performed before it can conclusively be said that this method produces more reliable results.

Once again, owing to the MFs high throughput capacity, it would be simple to run multiple assays within a limited timeframe. Relating to vessel isolation, exosome isolation has been shown to be an efficient process using MFs [77]. Exosomes are vesicles ranging from 30-150 nm in size [78] that occur naturally within the body and act as a transport medium for substances like miRNA, complex proteins, lipids and unwanted waste products. Exosomes can be exploited to assist with cancer diagnosis owing to unique markers being present on cancer-related exosomes. To list a few examples, melanoma is associated with CD63, and caveolin-1 biomarkers and acute myeloid leukemia is linked to TGF- $\mathrm{B}_{1}$ markers [79]. More examples can be found in Table 3 that could be exploited via an MF system. The isolation process is similar to that performed in studies by Varillas et al. and boasts a far less invasive procedure for the patient to obtain a diagnosis compared to a biopsy.

\subsection{Peptide-Conjugated Microbeads}

The final diagnostic application of peptide-based MFs presented in this review involves the incorporation of microbeads into the MF system for various diagnostic purposes, including the fast detection of $\mathrm{C}$ reactive protein (CRP), which has elevated levels in the body in the presence of inflammation. CRP is measured as standard during routine blood tests due to its importance for identifying life-threatening conditions, for instance, sepsis. An innovative design using immobilized antibodies on microbeads [80] was mixed, within the MF chip, with a diluted sample of human plasma, using a fluorinated oil as a surfactant to allow droplet formation within the chip. The sample was collected and incubated before being injected into a detection chip measuring fluorescent absorption to determine 
CRP concentration. The microbeads could be further adapted. For example, magnetic microbeads displaying unique peptide chains have already been shown to not only detect cancerous biomarkers but also to allow cell sorting within the MF chip, depending upon their bonding to the biomarkers [81].

Table 3. A small range of peptide biomarkers present during clinical analysis for specific conditions. To the best of our knowledge, biomarkers marked with * have yet to be diagnostically researched in conjunction with MFs.

\begin{tabular}{cc}
\hline Condition & Associated Peptide Biomarker(s) \\
\hline Leukemia & Transforming growth factor $\mathrm{B}_{1}\left(\mathrm{TGF}-\mathrm{B}_{1}\right)$ \\
Melanoma & Caveolin-1 \\
& CD63 \\
Alzheimer's disease & Apolipoprotein E (APOE) \\
Diabetes prediabetes & Hemoglobin A1c (HbA1c) \\
Breast cancer & HER2 \\
HIV / AIDS & Tissue polypeptide antigen * \\
\hline
\end{tabular}

It is common practice for detection to be incorporated into MF chips [82], as it allows faster and frequently more accurate compound detection. The use of the MF system provided a diagnostic sensitivity that was 10 times greater than conventional methods, allowing detection of CRP at concentrations of just $0.01 \mu \mathrm{gmL}^{-1}$ while also having the time required for diagnosis outcome. In the case of sepsis, where the time taken for diagnosis is an extremely important factor for determining prognosis [83], this new MF process could save many lives.

Theoretically, this diagnostic procedure could be applied to any of the proteins tested for during blood tests, such as hemoglobin, creatinine or thyroid-stimulating hormone (TSH). Microbeads have also been used creatively to provide simple point-of-care testing for various viruses, namely Ebola, Zika and Dengue. This technique exploits the physical formation of DNA hydrogels within the MF capillaries via rolling circle amplification (RCA) [84]. The microbeads are coated with genomic primer materials, complementary to that of the subject pathogen, and if the pathogen is present in the diagnostic sample, RCA occurs, causing the hydrogel formation, subsequently followed by MF capillary blockage. The blockage can be seen with the naked eye due to the presence of an additional dye within the MF chip.

As mentioned, this method allows point-of-care testing as no electricity is required to carry out the process; only a standard syringe to provide a weak vacuum is requisite for the test. It would be feasible for primers complementary to the genomic sequence of Covid-19 to be immobilized on the microbeads to allow rapid detection of the virus, as results obtained for pathogens by $\mathrm{Na}$ et al. [84] reduced the time of diagnosis from $2 \mathrm{~h}$ to just $15 \mathrm{~min}$.

\section{Future Perspectives}

In summation to the direction that peptide-based MFs should follow, it is clear that that the area of therapeutic peptides is generally underused, owing to the difficulty of medicine formulation. Initial studies indicate a promise to the MF platform to allow more successful manipulation of peptides. This is an area that could genuinely have a large impact upon providing a relatively untapped source of new medicines into fruition. For example, work like the one developed by Araújo, F. et al. [60] could provide viable oral peptide-based medicines for the first time, which would be a groundbreaking discovery, whilst the effective use of hydrogels produced via MFs could open the door to many bioregenerative processes, developing on an idea like Wu et al. [85] or Ghosh et al. [86]. While more difficult to obtain successful results, the area of therapeutic peptides is far 
less explored and could provide a greater degree of reward. The area of mRNA vaccine synthesis will likely become a highly sought-after process to optimize, and MFs could hold the key to this process if research is continued.

The focus for the future of MF diagnosis is already underway, as the platform continues to excel at building upon previously established techniques, such as standard immobilized antibody assays, and providing an optimizing feature, whether that be diagnostic time reduction [69] or yield increases [68]. There are still unexplored biomarkers that are opportunities for diagnostic research using MFs, as well as various in situ disease testing methods. The realization of the diagnostic capacity of MFs is seeing exponential growth in its use.

\section{Conclusions}

The speed and simplicity of MFs have lent themselves to increasing the popularity of the system as research within the area continues to grow exponentially. As peptide incorporation within the system is a relatively new concept, it can be expected that the interest and results obtained by combining the two will both increase and improve dramatically soon.

It is being realized how broad-spectrum the applications of MFs are for peptide theranostic purposes. However, due to a lack of research in the area, many processes are not yet optimized. Areas concerning peptide encapsulation are especially interesting due to the quality of the early results obtained, producing a standard of peptide medicine that has never been synthesized before. It is possible that developing this process will allow more complex, target-driven formulations, which could permit access to contemporary formulations, potentially even towards oral delivery of peptides. The diagnostic use of peptides within the MF system is particularly exciting due to the research rate being performed and the variability of its applications. It is clear that the performance of MFs is having a huge impact on establishing a new generation of peptide-based diagnostics.

Author Contributions: Writing-review and editing, E.W., S.U., D.K.C., A.H., D.A.L. All authors have read and agreed to the published version of the manuscript.

Funding: This project was funded by Immunocore.

Institutional Review Board Statement: Not applicable.

Informed Consent Statement: Not applicable.

Data Availability Statement: Not applicable.

Conflicts of Interest: The authors declare no conflict of interest.

\section{References}

1. Polypeptides and Proteins. 3 January 2021. Available online: https://bio.libretexts.org/@go/page/3426 (accessed on 29 April 2021).

2. Osorio, D.; Rondón-Villarreal, P.; Torres, R. Peptides: A package for data mining of antimicrobial peptides. Small 2015, 7, 4-14. [CrossRef]

3. Marqus, S.; Pirogova, E.; Piva, T.J. Evaluation of the use of therapeutic peptides for cancer treatment. J. Biomed. Sci. 2017, 24, 21. [CrossRef] [PubMed]

4. Hedges, J.B.; Ryan, K.S. Biosynthetic Pathways to Nonproteinogenic $\alpha$-Amino Acids. Chem. Rev. 2020, 120, 3161-3209. [CrossRef] [PubMed]

5. Marchese, L.; Nascimento, J.; Damasceno, F.; Bringaud, F.; Michels, P.; Silber, A. The Uptake and Metabolism of Amino Acids, and Their Unique Role in the Biology of Pathogenic Trypanosomatids. Pathogens 2018, 7, 36. [CrossRef] [PubMed]

6. Fosgerau, K.; Hoffmann, T. Peptide therapeutics: Current status and future directions. Drug Discov. Today 2015, 20, 122-128. [CrossRef] [PubMed]

7. Vllasaliu, D.; Thanou, M.; Stolnik, S.; Fowler, R. Recent advances in oral delivery of biologics: Nanomedicine and physical modes of delivery. Expert Opin. Drug Deliv. 2018, 15, 759-770. [CrossRef]

8. Meade, E.; Slattery, M.A.; Garvey, M. Bacteriocins, Potent Antimicrobial Peptides and the Fight against Multi Drug Resistant Species: Resistance Is Futile? Antibiotics 2020, 9, 32. [CrossRef]

9. Roudi, R.; Syn, N.L.; Roudbary, M. Antimicrobial Peptides As Biologic and Immunotherapeutic Agents against Cancer: A Comprehensive Overview. Front. Immunol. 2017, 8, 1320. [CrossRef] 
10. Cutone, A.; Rosa, L.; Ianiro, G.; Lepanto, M.S.; Bonaccorsi Di Patti, M.C.; Valenti, P.; Musci, G. Lactoferrin's Anti-Cancer Properties: Safety, Selectivity, and Wide Range of Action. Biomolecules 2020, 10, 456. [CrossRef]

11. Hazam, P.K.; Jerath, G.; Kumar, A.; Chaudhary, N.; Ramakrishnan, V. Effect of tacticity-derived topological constraints in bactericidal peptides. Biochim. Biophys. Acta Biomembr. 2017, 1859, 1388-1395. [CrossRef]

12. Otieno, B.A.; Krause, C.E.; Jones, A.L.; Kremer, R.B.; Rusling, J.F. Cancer Diagnostics via Ultrasensitive Multiplexed Detection of Parathyroid Hormone-Related Peptides with a Microfluidic Immunoarray. Anal. Chem. 2016, 88, 9269-9275. [CrossRef]

13. Kovalainen, M.; Mönkäre, J.; Riikonen, J.; Pesonen, U.; Vlasova, M.; Salonen, J.; Lehto, V.-P.; Järvinen, K.; Herzig, K.-H. Novel Delivery Systems for Improving the Clinical Use of Peptides. Pharmacol. Rev. 2015, 67, 541-561. [CrossRef]

14. Hosseini, S.F.; Ramezanzade, L.; McClements, D.J. Recent advances in nanoencapsulation of hydrophobic marine bioactives: Bioavailability, safety, and sensory attributes of nano-fortified functional foods. Trends Food Sci. Technol. 2021, 109, 322-339. [CrossRef]

15. Turecek, P.L.; Bossard, M.J.; Schoetens, F.; Ivens, I.A. PEGylation of Biopharmaceuticals: A Review of Chemistry and Nonclinical Safety Information of Approved Drugs. J. Pharm. Sci. 2016, 105, 460-475. [CrossRef] [PubMed]

16. Cao, M.; Xing, R.; Chang, R.; Wang, Y.; Yan, X. Peptide-coordination self-assembly for the precise design of theranostic nanodrugs. Coord. Chem. Rev. 2019, 397, 14-27. [CrossRef]

17. Knauer, N.; Pashkina, E.; Apartsin, E. Topological Aspects of the Design of Nanocarriers for Therapeutic Peptides and Proteins. Pharmaceutics 2019, 11, 91. [CrossRef] [PubMed]

18. Sibener, L.V.; Fernandes, R.A.; Kolawole, E.M.; Carbone, C.B.; Liu, F.; McAffee, D.; Birnbaum, M.E.; Yang, X.; Su, L.F.; Yu, W.; et al. Isolation of a Structural Mechanism for Uncoupling T Cell Receptor Signaling from Peptide-MHC Binding. Cell 2018, 174, 672-687. [CrossRef] [PubMed]

19. Sun, X.; Li, Y.; Liu, T.; Li, Z.; Zhang, X.; Chen, X. Peptide-based imaging agents for cancer detection. Adv. Drug Deliv. Rev. 2017, 110-111, 38-51. [CrossRef]

20. Convery, N.; Gadegaard, N. 30 years of microfluidics. Micro Nano Eng. 2019, 2, 76-91. [CrossRef]

21. Fei, S.; Hwang, W.; Mukherjee, A.; Chakrabarty, K. Defect-Oriented Testing and Diagnosis of Digital Microfluidicsbased Biochips. In Proceedings of the IEEE International Conference on Test, Austin, TX, USA, 8 November 2005.

22. Gogoi, S.; Gogoi, S.B. Review on microfluidic studies for EOR application. J. Pet. Explor. Prod. Technol. 2019, 9, $2263-2277$. [CrossRef]

23. Song, L.; Gao, W.; Rahmat-Samii, Y. 3-D Printed Microfluidics Channelizing Liquid Metal for Multipolarization Reconfigurable Extended E-Shaped Patch Antenna. IEEE Trans. Antennas Propag. 2020, 68, 6867-6878. [CrossRef]

24. Feng, J.; Yuan, J.; Cho, S.K. Micropropulsion by an acoustic bubble for navigating microfluidic spaces. Lab Chip 2015, 15, 1554-1562. [CrossRef] [PubMed]

25. Zhang, B.; Korolj, A.; Lai, B.F.L.; Radisic, M. Advances in organ-on-a-chip engineering. Nat. Rev. Mater. 2018, 3, 257-278. [CrossRef]

26. Ren, K.; Zhou, J.; Wu, H. Materials for Microfluidic Chip Fabrication. Acc. Chem. Res. 2013, 46, 2396-2406. [CrossRef] [PubMed]

27. Gupta, N.; Liu, J.R.; Patel, B.; Solomon, D.E.; Vaidya, B.; Gupta, V. Microfluidics-based 3D cell culture models: Utility in novel drug discovery and delivery research. Bioeng. Transl. Med. 2016, 1, 63-81. [CrossRef] [PubMed]

28. Ma, J.; Yan, S.; Miao, C.; Li, L.; Shi, W.; Liu, X.; Luo, Y.; Liu, T.; Lin, B.; Wu, W.; et al. Paper Microfluidics for Cell Analysis. Adv. Healthc. Mater. 2019, 8, 1801084. [CrossRef] [PubMed]

29. Zhu, Z.; Yang, C.J. Hydrogel Droplet Microfluidics for High-Throughput Single Molecule/Cell Analysis. Acc. Chem. Res. 2017, 50, 22-31. [CrossRef]

30. Pento, J.T. Monoclonal antibodies for the treatment of cancer. Anticancer Res. 2017, 37, 5935-5939.

31. Hildebrand, D.; Metz-Zumaran, C.; Jaschkowitz, G.; Heeg, K. Silencing SOCS1 via Liposome-Packed siRNA Sustains TLR4-Ligand Adjuvant. Front. Immunol. 2019, 10, 1279. [CrossRef]

32. Le, T.T.; Andreadakis, Z.; Kumar, A.; Román, R.G.; Tollefsen, S.; Saville, M.; Mayhew, S. The COVID-19 vaccine development landscape. Nat. Rev. Drug Discov. 2020, 19, 305-306. [CrossRef]

33. Koutsopoulos, S. Self-assembling peptide nanofiber hydrogels in tissue engineering and regenerative medicine: Progress, design guidelines, and applications. J. Biomed. Mater. Res. Part A 2016, 104, 1002-1016. [CrossRef]

34. Zhang, W.; Taheri-Ledari, R.; Hajizadeh, Z.; Zolfaghari, E.; Ahghari, M.R.; Maleki, A.; Hamblin, M.R.; Tian, Y. Enhanced activity of vancomycin by encapsulation in hybrid magnetic nanoparticles conjugated to a cell-penetrating peptide. Nanoscale 2020, 12, 3855-3870. [CrossRef] [PubMed]

35. McClements, D.J. Encapsulation, protection, and delivery of bioactive proteins and peptides using nanoparticle and microparticle systems: A review. Adv. Colloid Interface Sci. 2018, 253, 1-22. [CrossRef]

36. Wong, C.Y.; Al-Salami, H.; Dass, C.R. The role of chitosan on oral delivery of peptide-loaded nanoparticle formulation. J. Drug Target. 2018, 26, 551-562. [CrossRef] [PubMed]

37. Ross, C.; Taylor, M.; Fullwood, N.; Allsop, D. Liposome delivery systems for the treatment of Alzheimer's disease. Int. J. Nanomed. 2018, 13, 8507-8522. [CrossRef] [PubMed]

38. Ibaraki, H.; Kanazawa, T.; Kurano, T.; Oogi, C.; Takashima, Y.; Seta, Y. Anti-RelA siRNA-Encapsulated Flexible Liposome with Tight Junction-Opening Peptide as a Non-invasive Topical Therapeutic for Atopic Dermatitis. Biol. Pharm. Bull. 2019, 42, 1216-1225. [CrossRef] [PubMed] 
39. Lindqvist, A.; Rip, J.; van Kregten, J.; Gaillard, P.J.; Hammarlund-Udenaes, M. In vivo functional evaluation of increased brain delivery of the opioid peptide DAMGO by Glutathione-PEGylated liposomes. Pharm. Res. 2016, 33, 177-185. [CrossRef]

40. Oshima, A.; Sumitomo, K. Vesicle fusion with bilayer lipid membrane controlled by electrostatic interaction. Biochem. Biophys. Rep. 2017, 11, 58-63. [CrossRef]

41. Forbes, N.; Hussain, M.T.; Briuglia, M.L.; Edwards, D.P.; Horst, J.H.T.; Szita, N.; Perrie, Y. Rapid and scale-independent microfluidic manufacture of liposomes entrapping protein incorporating in-line purification and at-line size monitoring. Int. J. Pharm. 2019, 556, 68-81. [CrossRef]

42. Zhang, H. Thin-Film Hydration Followed by Extrusion Method for Liposome Preparation. Methods Mol. Biol. 2017, 1522, 17-22. [CrossRef]

43. Corey, L.; Mascola, J.R.; Fauci, A.S.; Collins, F.S. A strategic approach to COVID-19 vaccine R\&D. Science 2020, 368, 948-950. [CrossRef] [PubMed]

44. Leung, A.K.K.; Tam, Y.Y.C.; Chen, S.; Hafez, I.M.; Cullis, P.R. Microfluidic Mixing: A General Method for Encapsulating Macromolecules in Lipid Nanoparticle Systems. J. Phys. Chem. B 2015, 119, 8698-8706. [CrossRef]

45. Moon, H.-S.; Je, K.; Min, J.-W.; Park, D.; Han, K.-Y.; Shin, S.-H.; Park, W.-Y.; Yoo, C.E.; Kim, S.-H. Inertial-ordering-assisted droplet microfluidics for high-throughput single-cell RNA-sequencing. Lab Chip 2018, 18, 775-784. [CrossRef] [PubMed]

46. Taylor, N.; Elbaum-Garfinkle, S.; Vaidya, N.; Zhang, H.; Stone, H.A.; Brangwynne, C.P. Biophysical characterization of organellebased RNA/protein liquid phases using microfluidics. Soft Matter 2016, 12, 9142-9150. [CrossRef] [PubMed]

47. Lee, M.-H.; Lin, C.-C.; Thomas, J.L.; Chan, C.-K.; Lin, H.-Y. Epitope recognition of magnetic peptide-imprinted chitosan composite nanoparticles for the extraction of CRISPR/dCas9a proteins from transfected cells. Nanotechnology 2021, 32, 18LT02. [CrossRef]

48. Roozbehani, M.; Falak, R.; Mohammadi, M.; Hemphill, A.; Razmjou, E.; Meamar, A.R.; Masoori, L.; Khoshmirsafa, M.; Moradi, M.; Gharavi, M.J. Characterization of a multi-epitope peptide with selective MHC-binding capabilities encapsulated in PLGA nanoparticles as a novel vaccine candidate against Toxoplasma gondii infection. Vaccine 2018, 36, 6124-6132. [CrossRef]

49. Gessner, I.; Neundorf, I. Nanoparticles Modified with Cell-Penetrating Peptides: Conjugation Mechanisms, Physicochemical Properties, and Application in Cancer Diagnosis and Therapy. Int. J. Mol. Sci. 2020, 21, 2536. [CrossRef]

50. Field, L.D.; Delehanty, J.B.; Chen, Y.; Medintz, I.L. Peptides for Specifically Targeting Nanoparticles to Cellular Organelles: Quo Vadis? Acc. Chem. Res. 2015, 48, 1380-1390. [CrossRef]

51. Liu, K.; Li, H.; Williams, G.R.; Wu, J.; Zhu, L.-M. pH-responsive liposomes self-assembled from electrosprayed microparticles, and their drug release properties. Colloids Surfaces A Physicochem. Eng. Asp. 2018, 537, 20-27. [CrossRef]

52. Schiller, J.L.; Lai, S.K. Tuning Barrier Properties of Biological Hydrogels. ACS Appl. Bio Mater. 2020, 3, 2875-2890. [CrossRef]

53. Chan, K.H.; Tay, J.J.J. Advancement of Peptide Nanobiotechnology via Emerging Microfluidic Technology. Micromachines 2019, 10, 627. [CrossRef] [PubMed]

54. Cui, T.; Li, X.; He, S.; Xu, D.; Yin, L.; Huang, X.; Deng, S.; Yue, W.; Zhong, W. Instant Self-Assembly Peptide Hydrogel Encapsulation with Fibrous Alginate by Microfluidics for Infected Wound Healing. ACS Biomater. Sci. Eng. 2020, 6, 5001-5011. [CrossRef] [PubMed]

55. Jain, R.; Khandelwal, G.; Roy, S. Unraveling the Design Rules in Ultrashort Amyloid-Based Peptide Assemblies toward ShapeControlled Synthesis of Gold Nanoparticles. Langmuir 2019, 35, 5878-5889. [CrossRef] [PubMed]

56. Gireesha, B.; Sowmya, G.; Gorla, R.S.R. Nanoparticle shape effect on the thermal behaviour of moving longitudinal porous fin Proc. Inst. Mech. Eng. Part N J. Nanomater. Nanoeng. Nanosyst. 2020, 234, 115-121. [CrossRef]

57. Parsley, N.C.; Smythers, A.L.; Hicks, L.M. Implementation of Microfluidics for Antimicrobial Susceptibility Assays: Issues and Optimization Requirements. Front. Cell. Infect. Microbiol. 2020, 10, 547177. [CrossRef] [PubMed]

58. Di Santo, R.; Digiacomo, L.; Palchetti, S.; Palmieri, V.; Perini, G.; Pozzi, D.; Papi, M.; Caracciolo, G. Microfluidic manufacturing of surface-functionalized graphene oxide nanoflakes for gene delivery. Nanoscale 2019, 11, 2733-2741. [CrossRef] [PubMed]

59. Imani, R.; Emami, S.H.; Faghihi, S. Synthesis and characterization of an octaarginine functionalized graphene oxide nano-carrier for gene delivery applications. Phys. Chem. Chem. Phys. 2015, 17, 6328-6339. [CrossRef]

60. Araújo, F.; Shrestha, N.; Shahbazi, M.A.; Liu, D.; Herranz-Blanco, B.; Mäkilä, E.M.; Salonen, J.J.; Hirvonen, J.T.; Granja, P.L.; Sarmento, B.; et al. Microfluidic Assembly of a Multifunctional Tailorable Composite System Designed for Site Specific Combined Oral Delivery of Peptide Drugs. ACS Nano 2015, 9, 8291-8302. [CrossRef]

61. Unni, E.; Sternbach, N.; Goren, A. Using the Medication Adherence Reasons Scale (MAR-Scale) to identify the reasons for non-adherence across multiple disease conditions. Patient Prefer. Adherence 2019, 13, 993-1004. [CrossRef]

62. Cheang, J.Y.; Moyle, P.M. Glucagon-Like Peptide-1 (GLP-1)-Based Therapeutics: Current Status and Future Opportunities beyond Type 2 Diabetes. ChemMedChem 2018, 13, 662-671. [CrossRef]

63. Fiabane, J.; Prentice, P.; Pancholi, K. High Yielding Microbubble Production Method. BioMed Res. Int. 2016, $2016,3572827$. [CrossRef]

64. Pulsipher, K.W.; Hammer, D.A.; Lee, D.; Sehgal, C.M. Engineering Theranostic Microbubbles Using Microfluidics for Ultrasound Imaging and Therapy: A Review. Ultrasound Med. Biol. 2018, 44, 2441-2460. [CrossRef]

65. Angilè, F.E.; Vargo, K.B.; Sehgal, C.M.; Hammer, D.A.; Lee, D. Recombinant Protein-Stabilized Monodisperse Microbubbles with Tunable Size Using a Valve-Based Microfluidic Device. Langmuir 2014, 30, 12610-12618. [CrossRef]

66. Cumming, R.C.; Olberg, D.E.; Sutcliffe, J.L. Rapid18F-radiolabeling of peptides from [18F]fluoride using a single microfluidics device. RSC Adv. 2014, 4, 49529-49534. [CrossRef] 
67. Kesch, C.; Kratochwil, C.; Mier, W.; Kopka, K.; Giesel, F.L. 68Ga or18F for Prostate Cancer Imaging? J. Nucl. Med. 2017, 58, 687-688. [CrossRef] [PubMed]

68. Liu, Y.; Tian, M.; Zhang, H. Microfluidics for Synthesis of Peptide-Based PET Tracers. BioMed Res. Int. 2013, 2013, 1-8. [CrossRef]

69. Ni, M.; Tresset, G.; Iliescu, C.; Hauser, C.A.E. Ultrashort Peptide Theranostic Nanoparticles by Microfluidic-Assisted Rapid Solvent Exchange. IEEE Trans. NanoBiosci. 2020, 19, 627-632. [CrossRef]

70. Miles, J.J.; Tan, M.P.; Dolton, G.; Edwards, E.S.J.; Galloway, S.A.E.; Laugel, B.; Clement, M.; Makinde, J.; Ladell, K.; Matthews, K.K.; et al. Peptide mimic for influenza vaccination using nonnatural combinatorial chemistry. J. Clin. Investig. 2018, 128, 1569-1580. [CrossRef] [PubMed]

71. Srisa-Art, M.; Noblitt, S.D.; Krummel, A.T.; Henry, C.S. IR-Compatible PDMS microfluidic devices for monitoring of enzyme kinetics. Anal. Chim. Acta 2018, 1021, 95-102. [CrossRef] [PubMed]

72. Grant, J.; Goudarzi, S.H.; Mrksich, M. High-Throughput Enzyme Kinetics with 3D Microfluidics and Imaging SAMDI Mass Spectrometry. Anal. Chem. 2018, 90, 13096-13103. [CrossRef]

73. Briones, J.C.; Espulgar, W.V.; Koyama, S.; Yoshikawa, H.; Park, J.; Naito, Y.; Kumanogoh, A.; Tamiya, E.; Takamatsu, H.; Saito, M A Microfluidic Platform for Single Cell Fluorometric Granzyme B Profiling. Theranostics 2020, 10, 123-132. [CrossRef] [PubMed]

74. Hwang, H.K.; Kim, H.-I.; Kim, S.H.; Choi, J.; Kang, C.M.; Kim, K.S.; Lee, W.J. Prognostic impact of the tumor-infiltrating regulatory T-cell (Foxp3+)/activated cytotoxic T lymphocyte (granzyme B+) ratio on resected left-sided pancreatic cancer. Oncol. Lett. 2016, 12, 4477-4484. [CrossRef]

75. Varillas, J.I.; Zhang, J.; Chen, K.; Barnes, I.I.; Liu, C.; George, T.J.; Fan, Z.H. Microfluidic Isolation of Circulating Tumor Cells and Cancer Stem-Like Cells from Patients with Pancreatic Ductal Adenocarcinoma. Theranostics 2019, 9, 1417-1425. [CrossRef]

76. Safa, N.; Vaithiyanathan, M.; Sombolestani, S.; Charles, S.; Melvin, A.T. Population-based analysis of cell-penetrating peptide uptake using a microfluidic droplet trapping array. Anal. Bioanal. Chem. 2019, 411, 2729-2741. [CrossRef]

77. Suwatthanarak, T.; Thiodorus, I.A.; Tanaka, M.; Shimada, T.; Takeshita, D.; Yasui, T.; Baba, Y.; Okochi, M. Microfluidic-based capture and release of cancer-derived exosomes via peptide-nanowire hybrid interface. Lab Chip 2021, 21, 597-607. [CrossRef] [PubMed]

78. Yang, F.; Liao, X.; Tian, Y.; Li, G. Exosome separation using microfluidic systems: Size-based, immunoaffinity-based and dynamic methodologies. Biotechnol. J. 2017, 12, 1600699. [CrossRef] [PubMed]

79. Panagiotara, A.; Markou, A.; Lianidou, E.S.; Patrinos, G.P.; Katsila, T. Exosomes: A Cancer Theranostics Road Map. Public Health Genom. 2017, 20, 116-125. [CrossRef]

80. Tang, M.Y.H.; Shum, H.C. One-step immunoassay of C-reactive protein using droplet microfluidics. Lab Chip 2016, 16, 4359-4365. [CrossRef] [PubMed]

81. Cho, C.-F.; Ghotmi, Y.; Fazden, C.; Wolfe, J.; Bononi, F.; Murrell, E.; Luyt, L.; Viapiano, M.; Pentelute, B.; Chiocca, E.A.; et al. DDIS-19. Novel Peptide Homing to Glioma-Specific Isoform of Brevican Selectively Targets Malignant Brain Tumors. Neuro-Oncol. 2017, 19, vi62-vi63. [CrossRef]

82. Qi, J.; Li, B.; Wang, X.; Fu, L.; Luo, L.; Chen, L. Rotational Paper-Based Microfluidic-Chip Device for Multiplexed and Simultaneous Fluorescence Detection of Phenolic Pollutants Based on a Molecular-Imprinting Technique. Anal. Chem. 2018, 90, 11827-11834. [CrossRef] [PubMed]

83. Plunkett, A.; Tong, J. Sepsis in children. BMJ 2015, 350, h3017. [CrossRef] [PubMed]

84. Na, W.; Nam, D.; Lee, H.; Shin, S. Rapid molecular diagnosis of infectious viruses in microfluidics using DNA hydrogel formation. Biosens. Bioelectron. 2018, 108, 9-13. [CrossRef] [PubMed]

85. Wu, X.; He, L.; Li, W.; Li, H.; Wong, W.-M.; Ramakrishna, S.; Wu, W. Functional self-assembling peptide nanofiber hydrogel for peripheral nerve regeneration. Regen. Biomater. 2017, 4, 21-30. [CrossRef] [PubMed]

86. Ghosh, M.; Halperin-Sternfeld, M.; Grinberg, I.; Adler-Abramovich, L. Injectable Alginate-Peptide Composite Hydrogel as a Scaffold for Bone Tissue Regeneration. Nanomaterials 2019, 9, 497. [CrossRef] [PubMed] 